\title{
The Study of Adjustment Issues of University Students in Turkey under the Globalization of Education
}

\author{
Thseen Nazir ${ }^{1} \quad$ Sefa Bulut ${ }^{2}$
}

\begin{abstract}
Globally the mobilization of students tented from east to west where students prefer to travel and enroll in modern and advanced universities of west. They try to adapt the language, culture and new education system. Such trends happen in Turkey also in recent times and the universities in Turkey had seen a huge rise of enrolment of international students. The strength of International student's in higher education within the Turkey has increased considerably in the last few years with the help of different Turkish Scholarship Programs. The relevance of this work is determined by the adjustment issues of foreign student's adaptation to the educational environment of Turkish Universities. The study revealed that international students faces many challenges, which are categorized under academic challenges, social isolation, and cultural adjustment. In order to overcome these hurdles, challenges and barriers students have adopted and acclimatized different resources, which mainly are derived from the universities and outside universities in order to overcome all these challenges.
\end{abstract}

Keywords: Globalization, international students, academic challenges, issues, adjustment issues

\section{INTRODUCTION}

Globalization have affected education all around the world in many important and dramatic ways. The term "globalization" is not new and its meaning, nature, conceptualization, and impact remain controversial within the researcher community. It has been viewed as 'a set of processes by which the world is rapidly being integrated into one economic space via increased international trade, the internationalization of production and financial markets, and the internationalization of a commodity culture promoted by an increasingly networked global telecommunications system (Gibson, 2006). It is widely argued that the nature of contemporary globalization can be viewed as a multifaceted rather than a singular condition and that it is associated with various consequences at the economic, political and socio-cultural levels. Globalization as a concept refers both to the compression of the world and the intensification of consciousness of the world as a whole. There were objective changes taking place and the effect of these changes is people's subjective views of the world and their place within it (Robertson, 1992). The processes of globalization have not only widespread economic and political consequences, but also socio-cultural consequences. The power of cultural and informational interchange is creating a

\footnotetext{
${ }^{1}$ Assitant Prof.Dr. Thseen Nazir, Department of Counseling and Guidance, Ibn Haldun University, Istanbul,Turkey, thseen.nazir@ihu.edu.tr

${ }^{2}$ Prof. Dr. Sefa Bulut, Department of Counseling and Guidance, Ibn Haldun University, Istanbul, Turkey. sefa.bulut@ihu.edu.tr
} 
global society based upon a dense network of transnational exchanges and affiliations in a world where time and space are compressed (Castells, 1996).

\section{Globalization and Education}

From a historical point of view, globalization and education is interconnected with each other. The historical processes that is an essential forerunner to economic and political globalization in modern colonial eras influenced the growth of education. Thus, consider the current scenario we see around the world today as education and literacy movement scan as a first instance of impact on education by globalization. In many countries, other contextual traditional education had been conceived as smallscale, local community-based and as vocational or apprenticeship education, and/or religious training (Reagan, 2000). In most of the regions such as Africa, Asia, South America and Australasia, institutionalized formal schools emerged for the first time within colonial rule and spread throw missionary works.

The scholarships for education was introduced in colonial educational missions, such as in India, which was under the colonial rule of British Empire. This kind of scholarships served a purpose to create elite locals in order to serve colonial bureaucracy, train local people to work in industries that was benefiting the rulers. As postcolonial educational theorists such as Paulo Freire have seen it, this education sought to remove and dismiss local culture as inferior, and deny local community needs for the sake of power consolidation of elites, and it ultimately served as a system of oppression on psychological, cultural, and material levels (Freire ,1972).

With the time of dissolution of the colonial rules, the purpose of such kind of education was transformed and it took a shape with time under the light of globalization. This mass moment of students for education speeded up with rise of modern technology and it started enlightening the darkest parts of the world. Globalization also helped to transform the education system in every corner of the world by utilizing the modern technology and with means of new communication systems where people got excess to information from thousands of miles. Therefore, this trend continues and took the current shape, which we can understand by the fact as globally 4.6 million students are enrolled worldwide in 2017 and the USA remains the first choice for around 1.1 million international students. The second and third most preferred destinations are England and China hosting 11\% and 10\% respectively. According to the UNESCO Report, the international student's mobility will reach over 8 million by 2020 .

The recent drift by globalization across-borders, student mobility around the world has increased fundamentally and Turkey is not an exception. The inflow of international students in Turkey has increased significantly. According to the recent data published by Turkish Ministry, the total number of foreign students enrolled in Turkish universities for the educational year of 2016/2017 reached 103,727 individuals, with in rank, Azerbaijan, Syria and Turkmenistan contribute the highest percentage of foreign students coming to Turkey for study.

International students study in hundreds of universities all across Turkey. They contribute to the diversity of the university environment and social life. In one hand, they provide different perspectives during the courses and on another hand; they strengthen the mutual understanding of the differences found all across the globe. It is very necessary to embrace international students in Turkish university campuses. International students are extremely important to Turkish higher education for academic 
prestige and financial purposes. Many international students are bright and intellect however they have to meet requirements in academic and language aspects. These students bring diverse ways of thinking and enhance competition in academics.

International students are important part of diversity in the university campuses. With their own culture and ethnicity, they strengthen the cultural diversity of universities. They not only expose the students but they also expose the faculty members to this diversity and help them to develop theirs cultural sensitivities and skills in working with people from different backgrounds. International students can provide opportunities for Turkish faculty, students, and Turkish society to experience different languages, cultures, and traditions. Hammer, Bennett, and Wiseman (2003) discovered that "as one's experience of cultural difference become more complex and sophisticated, one's potential competence in intercultural relationship increases". Moreover, when an individual is exposed to such a diversity, the person has huge opportunity to construct a more diverse worldview and open his vision and ideology regarding the diverse nature of human. However, many international students face challenges as they pursue higher education outside of their home countries (Hull, 1978; Ozturgut, 2009). They face obstacles, such as different food, unfamiliar living circumstances, financial problems, balancing work, studying schedules, learning styles, or any difficulties related to language, culture, and personal barriers. A series of transitional difficulties can observed from daily life to cultural adaption (Constantine, 2009. Yoon, 2004). If Turkish universities are going to embrace international students in their campuses, these issues must be addressed. The current study is, therefore based on the international students who are hosted in Turkey in higher education for the past few years.

International students cannot escape the cultural shock and change they experience during their studies in the Turkey. Hence, these changes can be attributed to the acculturation process. These changes occur across physical, biological, cultural, social relationship, and psychological (behavior and mental health status) domains. Berry (2006) has proposed a transactional model of stress and coping in which he surmises that psychological health and adjustment is influenced by an individual's acculturation experience, the appraisal of acculturative stressors, and the coping skills used. The acculturation process can be positive, improving one's life chances and mental health in the majority/dominant culture, or it can be negative. The negative part of the acculturation process can occur due to the inherently challenging nature of change and adaptation to new cultural and social expectations (Berry, 1987). Similarly, the success of a sojourn or a temporary stay in a new culture is often conceived, in the psychological literature, in terms of "adjustment." It can occur in two aspects, namely, psychological and sociocultural adjustment (Ward, 1993). Psychological adjustments is defined as relating to the mental health and overall well-being of migrant (Ward, 1993), whereas sociocultural adjustment is defined as relating to the behavioral and cognitive factors that are associated with effective performance during cross-cultural transition (Sam, 2006).

\section{Literature Review}

Most international students entering Turkish universities can have an overwhelming life and huge cultural transition. Many studies explored the challenges and hurdles experienced by international students attending institutions of higher education in the Turkey and these difficulties include, language difficulties, difficulties adjusting to the academic culture, misunderstanding, and complications in 
communication with faculty and peers, stress, anxiety, feeling of isolation, social experiences, culture shock, lack of appropriate accommodation, isolation and loneliness (Nazir, 2018).

In many aspects, international students perceive the isolation and loneliness when they are studying in the Turkey. In a recent study conducted among 900 international students in Australia, found that $41 \%$ of international students experience substantial levels of stress. This stress could be from homesickness, cultural shock, or perceived discrimination (Russell, 2010). A recent study conducted in Turkey showed that $94 \%$ of the students had problems in adjusting to living in the Turkey (Nazir, 2018). Another study conducted in a major universities in Texas on the utilization of counseling services by international students and the data collected over six years of the study indicated that many international students, when having difficulties or psychological concerns, lean on family and friends (Yi, 2003). Unfortunately, not all students have the support they need and many people were not empathetic for hosting international students.

Many challenges also occur in the academic settings. Language is considered one of the greatest academic issues hindering smooth adjustment for international students (Galloway, 2005). A study survey staff experiences with international students and the findings indicated that the staff was not empathetic due to the student's language proficiency and they criticized international students for not taking responsibility for their academic advancement (Probertson, 2000). Liu (2011) used her own experiences as an example to discuss her struggles as an international student in Canada. Liu expressed that her lack of English proficiency became a barrier for successful participation in host community. She could not understand what her instructors and classmates were talking about in her graduate-level classes. She even had difficulty solving everyday problems, such as taking the correct buses, grocery shopping, or asking for help. Besides the isolation from classmates, many international students also face challenges from professors. For example, a study examined six international students' struggles in interacting with native speakers using ethnographic methods. Findings from this study showed that international students had to pretend to understand the conversational contents exchanged with native English speakers due to their limited language proficiency. At times, a low English proficiency level would result in a negative impression from a professor because the professor perceived that the international student was not well prepared for class (Terui, 2011). Similarly, another study also demonstrated a problem between a professor and their international students because of language proficiency. A study observed African female scientists who were graduate students in Western universities and the finding demonstrated that professors regularly questioned international student's ability to complete course assignments, encouraged international students to take remedial classes, and readily criticized international student's accents. The result of this type of treatment on behalf of the university professor prompted international students to feel that they did not have support when needed at school, and they perceived these responses from the professor as prejudicial attitudes toward them (Beoku-Betters, 2004). These studies show that international students lack support in their academic learning. Racism and stereotypes still exist for international students, and this is an important finding to consider that universities should consider when hosting international students.

On the contrary, a study found that students who feel at home, who are well connected to fellowstudents and professors and who take part in extracurricular activities are more likely to be retained in school and successfully graduate from the university. Namely, support from family and society has a positive influence on the study-success of students (Severiens, 2008). 
The above literature had discussed different examples from different populations, and these studies demonstrated the international student's acculturative stress. The acculturative stress refers to a variety of negative outcomes for international students. For example, the literature has noted that the challenges experienced by international students often trigger feelings of uneasiness, insecurity, depression, anxiety, and loss (Constantine, 2004; Wei, 2004) or academic pressures, language difficulties, feelings of inferiority, difficulties in adjusting to new food or cultural values, lack of support, perceived discrimination, and homesickness (Sandhu,1994; Yeh, 2003). Although challenges and coping strategies were discussed intensively in the literature, more studies are needed to examine these challenges, however, in different contexts

\section{METHOD}

In this research qualitative case study, method was adopted as per the need and purpose of this study. In order to have in depth understanding, issues of academic adaptation faced by international students studying in Turkey, case study method was used. Case study is the most appropriate qualitative research method for the present study because it "concentrates on experiential knowledge of the case and close attention to the influence of its social, political, and other contexts" (Stake, 2005).

\section{Participants}

The study identified twenty participants randomly as international students who were studying in undergraduate, graduate and doctorate programs in the different universities of Turkey. Among twenty participants 10 was male and 10 was female students. The representativeness was limited in this study as convenience sampling was used. However, in order to have more representativeness some demographic variables were controlled. So the participants were selected from different continents such as Asia, Africa and Europe. The participants were open and friendly and at the beginning, well repo was formed with them that allowed greater exploration of information, which was needed for this study. We met our participants at whatever place was convenient for them such as university campus, dormitories or in their convenient places. They basic criteria for selecting the participants were as follows.

1. They enrolled in university in the Turkey under the Graduation, Post-graduation or Doctorate Program.

2. The duration of residence was less than two years in Turkey

3. Students had experiences of taking language classes.

\section{Data Collection}

Interview sessions were held according to convince of participants such as at the university campus, apartments, dormitories in their convenient places. Each interview lasted 70 to 90 minutes and Interviews were audio taped and all participants was comfortable with recording and they all was assured it will be used for research purpose only and their identities will not be disclosed anywhere. The interview questions were related to international student's experiences in Turkey. The research adopted semi-structured interview so each participant will answer the same research question. The rationale of using this approach is to understand the respondent's point of view rather than 
generalizations of behaviors. All the Interviews were conducted in English as all the participants was comfortable with the English language.

\section{Data Analysis}

As per by many qualitative studies the data analysis was and primarily inductive which was guided by the early literature regarding the study. The complete individual information's were transcribed, then they were reviewed, and emerging themes were analyzed. These final categories of transcripts were as follows

1. The difficulties and struggles, which were encountered by participants in different situations such as academic, social, and cultural settings.

2. In order to resolve the issues what strategies they adopted.

3. Researcher's recommendations.

\section{FINDINGS}

Findings revealed that the international students in Turkey encountered different challenges and can be categorized such as academic, language and cultural aspects within the context of universities.

\section{Academic Barrier}

During the interviews, participants spent most of their time in discussing study related issues. Except undergraduate students, most participants regardless of their original background said that their teachers were nice, straightforward, and easy to approach. However, they had difficulties in communicating with them due to language barriers, cultural differences, and different expectations from professors. The themes which emerged after data analysis are as follows

> First theme was Communication with Professors. Most of the participants gave prime importance to the communication with their professors in the classrooms during the lessons. For example, most of the participants felt that they are not able to communicate with the professors because of the language barrier and they are not able to compete with other students who are native speakers of Turkish Language. Many times, there pronunciations seem awkward and they feel if they ask, questions or anything and other students will laugh. The fear of saying something wrong make them silent in their class as well as they are not able to communicate with their professors. Graduation students, who have huge number of enrolment in their classes, face this problem. In addition, communication hinders their participation in the class and it formulates a worse impression of them in front of professors as they are not able to participate actively in their lecture proceedings.

$>$ Second theme was isolation in Class. Most of the participants feel isolated in the class as isolation occurs when students try to fit in the environment and start making new friends. Analysis of most interviews found that International students have faced different kinds of isolation in classes. Many participants feel isolation and they are unable to make new friends in the class because of barriers such as language and culture. 
$>\quad$ Third theme was Language as a Barrier. Language is a means throw which we communicate our thoughts and ideas and in order to adapt and be adjusted in new culture language plays a pivotal role. In this study, the participants felt language is a greatest hindrance and it plays an important role in academic adjustment. Many participants said that Turkish language is a challenge in itself for them although they have studied Turkish language for one year in their language preparatory courses. Participants felt mostly that the language they learn in language preparatory courses are not enough and academic language looks very different. For many participants, they have to spend extra time improving their Turkish but speaking to them in day-to-day life in Turkish is different from the academic Turkish language. In one recent study conducted in Ankara and it had been found that $87 \%$ foreign students had problems in adjusting with Turkish Language Nazir, 2018).

$>$ Fourth theme was pressure from scholarship office or Family. Most of the participants felt pressure from the Concerned Scholarship office as they have to abide the rules and regulations and they have to fulfill all the criteria's otherwise their scholarship will be cut. These expectations included the learning outcome of Turkish language proficiency within a year; the completion of studies within a given time. In addition, on another side, their families had expectations on them and they want them to finish degree in time with good grades. Therefore, this pressure is continuous and it make situation worse especially when they are trying to adjust in new situations.

\section{Social Barrier}

$>\quad$ Fifth Theme was Communication Patterns. Under the social barrier, the first them emerged was communication pattern. Most of the students face difficulties in their daily social life. When these students join different social events in order to socialize and they had mentioned that in such events we struggle with the communication patterns. Participants also stated that the communication patterns, pronunciations and local slangs are very different and such slangs they face first time and it give them an awkward moments.

$>\quad$ Sixth theme is religion and religion related Practices. During the interview session, many participants share their experiences when they met local people and how people had ignored them completely if they belong to different religion or sect. It gave them a difficult time and made them reluctant to go to such a place again. For example as many participants shared their experiences when they introduce themselves and people was curious to know about their religion and the sect they belong. The questions goes on like....Are you Muslim. In addition, the Shai or Sunni? If the answer is different from what they themselves believe on, the conversations completely end up without saying a word, and people literally ignore onwards.

\section{Adjustment Strategies}

There are hundreds of Researches, who had evidenced that international students experience an adjustment challenges and it can influence their study and overall experience. Adjustment and getting adapted to the new environment is a basic task for every organism and it can have a profound effect on round up development of a person, affect him as a whole person, and shape his personality. Therefore, people plan and apply different strategies in such situations in order to be adjusted and adapt the situation. 
$>$ Seventh Theme was Dormitory and Campus Activities. Living in a dormitory and with a person who belongs to very naive culture and may not understand you is a huge challenge. However, such situation gives you an opportunity where you can learn and adapt situation easily as it provides you a daily basis exposure to the situation. Some participants started to look for native Turkish speaking friends in order to improve their Turkish proficiency. One of participants joined different student social clubs and other non-governmental organizations that give them platform to learn and meet different people. Through such socialization, students would like to share their cultures to other students at campus, and they would like to immerse themselves to interact with other Turkish native speakers.

$>\quad$ The eighth theme was Language Support. Usually in general students mostly show proficiency in speaking daily dialects but in an academic environment while discussing things with their professors or in the class, they face problems. Many students admitted that the language classes do not give them in-depth command on Turkish language, which is necessary for academics, and they face trouble even writing a small note of homework. Also for many international students, Turkish academic system is naive and difficult so they need to be guided and helped. After finishing their language courses, they do not find any Language support system in the universities, which can help them in sharpening their language skills.

\section{DISCUSSION}

The degree of difficulty in adjustment varied from person to person in any context and it is the case with the every student. The study had identified and categorized it under three area in which international students face challenges and adjustment issues in Turkey. Each category is having various sub-themes, which show the challenges in these areas. The first one is academic barrier under which students face issues related to academics i.e. Communication with professor, Isolation in class, Language as a barrier and pressure from scholarship office. Mostly research had found that Language barrier is one of the biggest challenge for international students whether it is with professor or it is in dormitories or dealing with local people. One of the greatest issues in academic adjustment for international students is language (Galloway, 2005). For International student's instructional style of a teacher can act as a barrier in learning (Laad, 1999). A study in Ankara, Turkey had asked international students to rank the adjustment issues according to the toughness and $94 \%$ of the students ranked language barrier as the toughest adjustment barrier among ten other adjustment areas (Nazir, 2017). All these researches had showed that language becomes a communication barrier, which make the international students adjustment process hard and make them struggle. Among the Social barrier, mostly studies found communication pattern, religion, and practices related to religion works becomes barriers in international student's adjustment process. The communication and the pattern of communication such as slang or the pronunciation, local accent sometimes makes it hard too. Studies supported the view that higher language skills is positively correlated with the adjustment (Ward, 1999). This is because many scholars believe that host language competence is at the center of the acculturation process (Verthelyi, 1995). Mostly in every kind of adjustment for international students whether it is in academic life or social life, communication plays a vital role. The study findings alien with the findings across the world 
where for example International students in America, Canada, China, Indonesia, Australia face similar kind of problems as in Turkey because of communication barriers and differences in Cultural front.

\section{CONCLUSION}

The study used qualitative research design and tried to explore academic, cultural and social adaptation of international students and in order to maintain the generalization under consideration this study includes participants from diverse background such as Asia, Africa and Europe. The findings try to put a light on various adjustment issues which an international students face as they are enrolled in different universities in Turkey. These challenges and issues on one side create adjustment challenges to these students but also they get motivated to develop the new strategies in order to solve these problems and challenges. With duration of time, they transform themselves in new environment, which is continuously demanding, and they develop strategies to deal with all those challenges. All these challenges and adjustment need time and lot of their efforts and they need regular support from different sources so they can overcome these challenges successfully and achieve their academic goals. Universities are the first seat of resources which can provide them a setback in terms of support and can provide them a helpful environment where these international students can bloom in full pace. Thus, the university needs to focus on the challenges faced by international students and provide more adequate and friendly support for them.

\section{REFERENCES}

Ashcroft, B., Griffiths, G., \& Tiffin, H. (Eds.) (1995). The post-colonial studies reader. London: Routledge.

Beoku-Betts, J. A. (2004). African Women Pursuing Graduate Studies in the Sciences: Racism, Gender Bias, and Third World Marginality. NWSA Journal, 16(1), 116-135.

Berry, J. W., Kim, U., Minde, T., \& Mok, D. (1987). Comparative Studies of acculturative stress (Canada), International Migration Review, 21(3), 491-511.

Berry, J. W. (2006). Acculturative stress, in Handbook of Multicultural Perspective on Stress and Coping. P. T. P. Wong and L. C. J. Wong, Eds., 287-298, Springer, New York, NY, USA.

Constantine, S., Okazaki, \& Utsey, S. O. (2004).Self-concealment, social self-efficacy, acculturative stress, and depression in African, Asian, and Latin American international college students. American Journal of Orthopsychiatry, 74(3), 230-241.

Constantine, M. G., Kindaichi, M., Okazaki, S., Gainor, K. A., \& Baden, A. L. (2005) A qualitative investigation of the cultural adjustment experiences of Asian international college women. Cultural Diversity and Ethnic Minority Psychology, 11(2), 162-175.

Freire. P, (1972), Pedagogy of the oppressed (Victoria: Penguin).

Galloway, F. J., \& Jenkins, J. R. (2005). The adjustment problems faced by international students in the United States: a comparison of international students and administrative perceptions at two private, religiously affiliated universities. NASP A Journal, 42(2), 175-187. 
Hammer, M. R., Bennett, M. J., \& Wiseman. (2003). The intercultural development inventory: a measure of intercultural sensitivity, International Journal of Intercultural Relations, 27, 421-443.

Hull, W. F., (1978). Foreign Students in the United States of America: Coping Behavior within the Education Environment. Praeger, New York, NY, USA.

Liu. (2011). An international graduate student's ESL learning experience beyond the classroom. TESL Canada Journal, 29(1), 77-92.

Nazir, T. (2017). Adaptation challenges of International students, who come to study in Turkey under Turkey Bursları scholarship International Social Science Congress Istanbul. International Students Social Sciences Congress Proceedings - i, ilmietüdlerderneği, isbn: 978-605-68401-4-2 (1.c), 523-526.

Özturgut, O., \& Murphy, C. (2009). Literature vs. practice: challenges for international students in the US. International Journal of Teaching and Learning in Higher Education, 22(3), 374-385.

Robertson, M., Line, M., Jones, S., \& Thomas, S. (2000). International students, learning environments and perceptions: A case study using the Delphi technique. Higher education research $\mathcal{E}$ development, 19(1), 89-102.

Reagan, T. (2000). Non-Western educational traditions: Alternative approaches to educational thought (Mahwah, NJ: Lawrence Erlbaum). Of course, scholars such as Michael P. Smith would reject describing these processes as belonging to globalization, as people, nations, and communities played significant roles.

Reinharz, (1992). Feminist methods in social research. Oxford University Press, New York, NY, USA.

Russell, J., Rosenthal, D., \& Thomson, G. (2010). The international student experience: Three styles of adaptation. Higher Education, 60(1), 235-249.

Sam, D. L., Vedder, P., Ward, C., \& Horenczyk, G. (2006). Psychological and sociological adaptation of immigrant youth. In J. W. Berry, J. S. Phinney, D. L. Sam, \& P. Vedder (Eds), Immigtant youth in cultural transition: Acculturation, identity, and adaptation across national contexts (pp. 117-141). New Jersey, Lawrence Erlbaum Associates.

Sandhu, D. S., \& Asrabadi, B. R. (1994). Development of an acculturative stress scale for international students: Preliminary findings. Psychological reports, 75(1), 435-448.

Severiens, S., \& Wolff, R. (2008). A comparison of ethnic minority and majority students: Social and academic integration, and quality of learning. Studies in higher education, 33(3), 253-266.

Stake, R. E. (2005). Qualitative case study. In N. Denzin, \& Y. Lincoln (Eds). Handbook of qualitative research (pp. 443-466). Sage.

Terui, S. (2011). Second language learners' coping strategy in conversations with native speakers. Journal of International Students, 2(2), 168-183.

Yeh, C. J., \& Inose, M. (2003). International students' reported English fluency, social support satisfaction, and social connectedness as predictors of acculturative stress. Counselling Psychology Quarterly, 16(1), 15-28. 
Yi, J. K., Lin, J. C. G., Jenny, K., \& Kishimoto, Y. (2003). Utilization of counseling services by international students. Journal of Instructional Psychology, 30(4), 333-346.

Yoon. E., \& Portman, T. A. A. (2004). Critical issues of literature on counseling international students. Journal of Multicultural Counseling and Development, 32(1), 33-44.

Ward. C., \& Kennedy. A., (1993). Where's the culture in cross-cultural transition? Comparative studies of sojourner adjustment. Journal of Cross-Cultural Psychology, 24(2), 221-249.

Wei, M., Heppner, P. P., Mallen, M. J., Ku, T. Y., Liao, K. Y. H., \& Wu, T. F. (2007). Acculturative stress, perfectionism, years in the United States, and depression among Chinese international students. Journal of Counseling Psychology, 54(4), 385-394. 